\title{
Prevalence of Latent Tuberculosis among Hospital Administrative Staff in Kuala Lumpur
}

\author{
Mohd Hasni Jaafar, Kumaren Krishnan \\ Department of Community Health, Universiti Kebangsaan Malaysia Medical Centre, Kuala Lumpur, Malaysia
}

\begin{tabular}{l} 
Article Info \\
\hline Article history: \\
Received Jun 23, 2016 \\
Revised Aug 10, 2016 \\
Accepted Aug 20, 2016 \\
\hline
\end{tabular}

\section{Keyword:}

Administrative job

Health care workers

Latent tuberculosis infection

Male

Young

\begin{abstract}
In the United States, there were about 10 to 15 million people with latent tuberculosis infection (LTBI) who are asymptomatic, particularly among healthcare workers (HCWs). The aim of the study was to determine the prevalence of LTBI among the HCWs in a main general hospital in Malaysia. About 401 HCWs have been enrolled in this cross sectional study conducted in November 2014 until January 2015. A standardised questionnaire was used to obtain their demography and job description together with Tuberculin skin test (TST). The prevalence of LTBI in the institution was about $46.4 \%$, which was high. It was common amongst a younger age group and male HCWs. The noble finding was the study proved that the administrative type of work in a clinical setting has the highest prevalence and risk (adjusted OR=5.366; 95\% CI=1.397-20.619) compared to others. Non-clinical HCWs like administrator should be treated as one of potential job for TBI in any hospital or clinic. Any programme on TBI awareness and prevention should include them too.
\end{abstract}

Copyright (C) 2016 Institute of Advanced Engineering and Science. All rights reserved.

\section{Corresponding Author:}

Mohd Hasni Ja’afar,

Department of Community Health,

University Kebangsaan Malaysia Medical Centre,

Kuala Lumpur, Malaysia Tel: +603-91455720; Fax: +603-91456670.

Email: drmhasni65@hotmail.com

\section{INTRODUCTION}

Tuberculosis as one of the most dangerous infectious agents, second after the human immunodeficiency infection virus (HIV). In 2012, about 8.6 million people infected with tuberculosis (TB) and 1.3 million died from it [1]. And about one-third of the world's population has latent TB infection (LTBI), which means they have been infected with TB bacteria but are not yet ill with the disease [2].Among some of the most vulnerable population to this resurgence of TB infections are healthcare workers (HCWs) as they are on the front line of being exposed to diseased patients who are often asymptomatic in the early stage and do not know that they have the disease [3],[4]. And various studies revealed the increased number of LTBI amongst HCWs [5]-[7].

In detection of TB infection, the Tuberculin Skin Test (TST) is still being used everywhere, although its reliability was questionable [8]-[10]. In Malaysia, it is the standard testing kit for TB and made available at all government hospitals. However, not all HCWs in the government sector are screened for LTBI. Thus the study was carried out, for the first time, to ascertain the prevalence of LTBI amongst healthcare workers in one of the main general hospital using TST as well as to determine their associated factors. 


\section{RESEARCH METHOD}

This cross sectional study was conducted between November 2014 until January 2015 among 401 permanent healthcare workers in a government general hospital. The respondents were selected from the administrative list using simple random sampling. Each of them was asked to answer a standardised questionnaire and undergo TST. The questionnaire includes demographic and co-morbid information. For TST reading, three occupational nurses were sent for a TST administration and reading course conducted by a local recognised Institute of Respiratory Medicine for one week. Written consent was obtained from each respondent before the enrollment. The data were analysed using SPSS statistics version 21.0 (SPSS, Chicago, IL, USA) with the significant point of $\mathrm{p}<0.05$. The study has received ethics approval from the Medical Research and Ethics Committee of Ministry of Health, and from the National University of Malaysia committee.

\section{RESULTS AND ANALYSIS}

A total number of 401 HCWs was involved in this study as shown Table 1 . The majority of them aged between 20 to 29-year-old (51.7\%), followed by the middle age group of 30 to 49-year-old (39.6\%), and senior group of HCWs (8.7\%) aged more than 50 years. Most of them were female HCWs (78.8\%). More than half (54.9\%) of the respondents work in the allied health sector, such as medical assistants, staff nurses, sisters and matrons, and assistant pharmacists. Only about $4.2 \%$ of the enrolled respondents work in the administrative sector, such as clerks and admin officers.

Table 1. Respondents’ baseline characteristics

\begin{tabular}{lc}
\hline Variable & Value (\%) \\
\hline $\mathrm{n} \quad$ & 401 \\
Age group (year), n (\%) & $207(51.7)$ \\
$20-29$ & $77(19.2)$ \\
$30-39$ & $82(20.4)$ \\
$40-49$ & $35(8.7)$ \\
$>50$ & \\
Gender, n (\%) & $85(21.2)$ \\
Male & $316(78.8)$ \\
Female & \\
Job description, n (\%) & $39(9.7)$ \\
Professional & $220(54.9)$ \\
Allied Health & $125(31.2)$ \\
Support staff & $17(4.2)$ \\
Administration & \\
Workplace, n (\%) & $79(19.7)$ \\
Medical wards & $60(15.0)$ \\
Surgical wards & $66(16.5)$ \\
Clinic / Pharmacy & $140(34.8)$ \\
Emergency / Operation Theater & $22(5.5)$ \\
Intensive care units & $34(8.5)$ \\
Admin office &
\end{tabular}

The prevalence of LTBI among the respondents was 46.4\%. In comparison, of LTBI occurrence in between the respondents age groups, the age group member of 30 to 39-year-old have the highest percentage of $48.1 \%$ as shown in Table 2 . The second highest was among the youngest age group members with a prevalence of $46.4 \%$, followed by the senior group (45.7\%) and less senior group (45.1\%). The differences were significant with $\mathrm{p}<0.01$, in which the prevalence of LTBI was obviously high among the young HCWs. And again, it was significantly higher in male compared to female HCWs, $47.1 \%$ and $46.2 \%$ respectively. Those involved as health administration, the study found a prominent high percentage of LTBI occurrence among them (70.6\%) compared to other job descriptions. In addition, those who only work in the admin office were also found positive with LTBI (55.9\%) which is the highest rate compared to other work site or place.

Variables like age groups and gender give two times higher risk, but were not significant ( $\mathrm{p}>0.05)$. However, after adjusting for age and gender factors, the study revealed that only those who are involved in administrative work do have a higher risk of LTBI compared to other job specification (adjusted OR=5.366; $95 \%$ CI=1.397-20.619) as shown in Table 3. 
Table 2. Bivariate analysis on LTBI and respondent characteristics

\begin{tabular}{|c|c|c|c|}
\hline \multirow{2}{*}{ Variable } & \multicolumn{2}{|c|}{ LTBI } & \multirow{2}{*}{$P$ value } \\
\hline & Yes & No & \\
\hline Age group (year), n (\%) & & & $0.001^{* *}$ \\
\hline $20-29$ & $96(46.4)$ & $111(53.6)$ & \\
\hline $30-39$ & 37 (48.1) & $40(51.9)$ & \\
\hline $40-49$ & $37(45.1)$ & $45(54.9)$ & \\
\hline$>50$ & $16(45.7)$ & $19(54.3)$ & \\
\hline Gender, n (\%) & & & $0.001 * *$ \\
\hline Male & $40(47.1)$ & 45 (52.9) & \\
\hline Female & $146(46.2)$ & $170(53.3)$ & \\
\hline Job description, n (\%) & & & $0.030 *$ \\
\hline Professional & $16(41.0)$ & $23(59.0)$ & \\
\hline Allied Health & $99(45.0)$ & $121(55.0)$ & \\
\hline Support staff & $59(47.2)$ & $66(52.8)$ & \\
\hline Administration & $12(70.6)$ & $5(29.4)$ & \\
\hline Workplace, n (\%) & & & $0.001 * *$ \\
\hline Medical wards & 35 (44.3) & $44(55.7)$ & \\
\hline Surgical wards & $29(48.3)$ & 31 (51.7) & \\
\hline Clinic / Pharmacy & $32(48.5)$ & $34(51.5)$ & \\
\hline Emergency / Operation Theater & $63(45.0)$ & $77(55.0)$ & \\
\hline Intensive care units & $8(36.4)$ & $14(63.6)$ & \\
\hline Admin office & $19(55.9)$ & $15(44.1)$ & \\
\hline
\end{tabular}

Table 3. Multivariate analysis on LTBI and respondent characteristics

\begin{tabular}{lccc}
\hline Variable & $\beta$ & $\begin{array}{c}\text { Adj. Odds ratio } \\
\text { (OR) }\end{array}$ & $\begin{array}{c}\text { 95\% Confidence } \\
\text { Interval }\end{array}$ \\
\hline Age group & 0.054 & 1.055 & $0.320-3.480$ \\
Gender & 0.118 & 1.125 & $0.332-3.813$ \\
Job description & 1.680 & 5.366 & $1.397-20.619$ \\
\hline
\end{tabular}

\section{DISCUSSION}

The study exposed that the prevalence of LTBI was about $46.4 \%$ among the HCWs in one of the main government general hospital. It was higher compared to Germany (10.0\%) [11], but was comparable with the finding from Saudi Arabia (46.1\%) [12]. And the rate was comparatively lower than other countries like South Africa (56.7\%) [13], Taiwan (88.8\%) [14], and China (56.7\%) [15].

Another study discovery was about the high prevalence of LTBI among young HCWs. It was supported by various studies than finding young age as one of the important factors for TBI [16]-[19]. However, some studies also found more cases of LTBI among older HCWs which in favour of this study finding [20]-[21].

LTBI was found to be higher among male than female HCWs as found by other studies. However, some studies showed the opposite gender [22]-[24]. It also showed that the risk of infection was dissimilar across the job description [25]. And for this study, health administrators were at higher risk of getting LTBI. It might be due to inadequate of knowledge, attitude and practise about prevention of TB infection [26]-[27].

\section{CONCLUSION}

This is the only study that revealed a high occurrence of TBI among non-clinical HCWs, administrative staff. They also need to have good knowledge and know the best practise in preventing the disease. The TB prevention programme should also include them as one of the potential participants in future. And they should be also included as one of the high risk groups among the healthcare workers in any health setting. Those non-clinical healthcare workers are actually at high risk of tuberculosis infection and need to be included in any prevention and monitoring activities that related. They have a great potential as the source of nosocomial tuberculosis to other patients and staffs.

\section{ACKNOWLEDGEMENT}

The study would like to thank the hospital director and other supporting staffs for their full support and assistant until the end of this research. 


\section{REFERENCES}

[1] World Health Organization, “Global tuberculosis report,” Geneva, 2013.

[2] Mack U., Migliori G. B., Sester M., et al., "Lange for the TBNET. LTBI: latent tuberculosis infection or lasting immune responses to M. Tuberculosis? A TBNET consensus statement,” Eur Respir J., vol. 33, pp. 956-73, 2009.

[3] Pan S. C., Chen Y. C., Wang J. Y., et al., "Tuberculosis in Healthcare Workers: A Matched Cohort Study in Taiwan,” PLoS One, vol. 10, pp. e0145047, 2015.

[4] O'Hara N. N., Roy L., O'Hara L. M., et al., "Healthcare Worker Preferences for Active Tuberculosis Case Finding Programs in South Africa: A Best-Worst Scaling Choice Experiment,” PLoS One, vol. 10, pp. e0133304, 2015.

[5] Joshi R., Reingold A. L., Menzies D., Pai M., "Tuberculosis among health-care workers in low-and middle-income countries: a systematic review,” PLoS Medicine, vol. 3, pp. e494, 2006.

[6] Mirtskhulava V., Whitaker J. A., Kipiani M., et al., "Determinants of tuberculosis infection control-related behaviors among healthcare workers in the country of Georgia,” Infect Control Hosp Epidemiol, vol. 36, pp. 522-8, 2015

[7] Chu H., Shih C. J., Lee Y. J., et al., "Risk of tuberculosis among healthcare workers in an intermediate-burden country: a nationwide population study,” The Journal of Infection, vol. 69, pp. 525-32, 2014.

[8] Al-Zamel F. A., "Detection and diagnosis of Mycobacterium tuberculosis," Expert Review Of Anti-Infective Therapy, vol/issue: 7(9), pp. 1099-108, 2009.

[9] Diel R., Goletti D., Ferrara G., et al., "Interferon-gamma release assays for the diagnosis of latent Mycobacterium tuberculosis infection: a systematic review and meta-analysis,” The European Respiratory Journal, vol. 37, pp. 8899, 2011.

[10] Lighter F. J., Surette A. M., "Performance of an interferon-gamma release assay to diagnose latent tuberculosis infection during pregnancy,” Obstetrics and Gynecology, vol. 119, pp. 1088-95, 2012.

[11] Nienhaus A., Schablon A., Preisser A. M., et al., "Tuberculosis in healthcare workers - a narrative review from a German perspective,” J Occup Med Toxicol, vol. 9, pp. 9, 2014.

[12] Balkhy H. H., Miller T. L., Ali S., et al., "Compliance with post exposure screening and treatment of latent tuberculosis infection among healthcare workers in a tertiary care hospital in Saudi Arabia,” Infect Control Hosp Epidemiol, vol. 35, pp. 176-81, 2014.

[13] van Rie A., McCarthy K., Scott L., et al., "Prevalence, risk factors and risk perception of tuberculosis infection among medical students and healthcare workers in Johannesburg, South Africa,” S Afr Med J., vol. 103, pp. 853-7, 2013.

[14] Hung W. T., Lee S. S., Sy C. L., et al., "Prevalence of latent tuberculosis infection in BCG-vaccinated healthcare workers by using an interferon-gamma release assay and the tuberculin skin test in an intermediate tuberculosis burden country,” J Microbiol Immunol Infect, vol. 48, pp. 147-52, 2015.

[15] Wei Z., Yang M., Quan B., et al., "Prevalence of latent tuberculosis infection among healthcare workers in China as detected by two interferon-gamma release assays,” The Journal of hospital infection, vol. 84, pp. 323-5, 2013.

[16] Gounder P. P., Harris T. G., Anger H., et al., "Risk for Tuberculosis Disease among Contacts with Prior Positive Tuberculin Skin Test: A retrospective Cohort Study, New York City,” Journal Of General Internal Medicine, vol. 30, pp. 742-8, 2015.

[17] Saunders M. J., Koh G. C., Small A. D., Dedicoat M., "Predictors of contact tracing completion and outcomes in tuberculosis: A 21-year retrospective cohort study,” Int J Tuberc Lung Dis., vol. 18, pp. 640-6, 2014.

[18] El-Helaly M., Khan W., El-Saed A., Balkhy H. H., "Pre-employment screening of latent tuberculosis infection among healthcare workers using tuberculin skin test and QuantiFERON-TB Gold test at a tertiary care hospital in Saudi Arabia,” Journal of Infection and Public Health, vol. 7, pp. 481-8, 2014.

[19] Schaaf H. S., Collins A., Bekker A., Davies P. D., "Tuberculosis at extremes of age,” Respirology, vol. 15, pp. 74763, 2010.

[20] Whitaker J. A., Mirtskhulava V., Kipiani M., et al., "Prevalence and incidence of latent tuberculosis infection in Georgian health care workers,” PLoS One, vol. 8, pp. e58202, 2013.

[21] Guanche G. H., Crespo R. E., Kindelan C. A., Garcia F. G., "Latent tuberculosis infection in healthcare workers at a community hospital in Qatar,” Journal of Infection and Public Health, vol. 7, pp. 356-9, 2014.

[22] Lambert L. A., Pratt R. H., Armstrong L. R., et al., “Tuberculosis among healthcare workers, United States, 19952007,” Infect Control Hosp Epidemiol, vol. 33, pp. 1126-32, 2012.

[23] Kizza F. N., List J., Nkwata A. K., et al., "Prevalence of latent tuberculosis infection and associated risk factors in an urban African setting,” BMC Infectious Diseases, vol. 15, pp. 165, 2015.

[24] Khawcharoenporn T., Apisarnthanarak A., Phetsuksiri B., "Tuberculin skin test and QuantiFERON-TB Gold Intube Test for latent tuberculosis in Thai HIV-infected adults,” Respirology, vol. 20, pp. 340-7, 2015.

[25] Zhang X., Jia H., Liu F., et al., "Prevalence and Risk Factors for Latent Tuberculosis Infection among Health Care Workers in China: A Cross-Sectional Study,” PLoS One, vol. 8, pp. e66412, 2013.

[26] Gao J., Berry N. S., Taylor D., et al., "Knowledge and Perceptions of Latent Tuberculosis Infection among Chinese Immigrants in a Canadian Urban Centre,” International Journal of Family Medicine, Article No: 546042, 2015.

[27] He G. X., van den Hof S., van der Werf M. J., et al., "Infection control and the burden of tuberculosis infection and disease in health care workers in China: a cross-sectional study,” BMC Infectious Diseases, vol. 10, pp. 313, 2010. 


\section{BIOGRAPHIES OF AUTHORS}

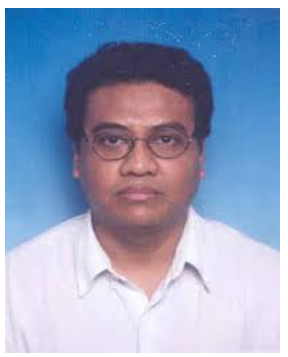

Dr. Mohd Hasni Jaafar is a senior medical lecturer at Department of Community Health, Faculty of Medicine, University Kebangsaan Malaysia.

Dr. Kumaren Krishnan is a master scholar for Public Health at Department of Community Health, Faculty of Medicine, Universiti Kebangsaan Malaysia 